The Polish Journal of the Arts and Culture. New Series 6

(2/2017): 29-52 [ARTICLE]

DOI: $10.4467 / 24506249$ PJ.17.009.8763

\title{
Esbozos etnográficos entorno a una entidad sagrada maya peninsular: los aluxo'ob.
}

\author{
David DE ÁNGEL GARCÍA
}

\begin{abstract}
Resumen
El presente trabajo ofrece un acercamiento a una de las entidades sagradas de raigambre indígena que se ha mantenido actuante con mayor vigor en la cosmología maya peninsular. A partir de datos etnográficos recabados en poblaciones nativas del estado mexicano de Campeche, el texto trata de ilustrar el papel central que desempeñan los aluxo'ob como destinatarios de un buen número de los rituales de ofrendas que realizan anualmente los campesinos mayas, así como su protagonismo en diversos relatos mitológicos sobre los orígenes del mundo y las sucesivas creaciones y destrucciones de las humanidades que lo habitaron. Finalmente, se explora los vínculos que establecen los especialistas rituales mayas (jmeen) con los aluxo'ob, a quienes recurren en busca de los conocimientos esotéricos que les permiten desempeñarse como mediadores entre la comunidad y las entidades sagradas.
\end{abstract}

Palabras clave: mayas peninsulares, aluxo'ob, cosmología, rituales, jmeen

David de Ángel García Investigador titular del Centro Peninsular en Humanidades y en Ciencias Sociales de la Universidad Nacional Autónoma de México, ubicado en Mérida, Yucatán.

E-MAIL: corle_spck@yahoo.es 
El alux es quizás una de las figuras más reconocidas y representativas de la cosmovisión maya peninsular. Desde las selvas de Quintana Roo habitadas por los cruzo'ob, descendientes de los mayas rebeldes que protagonizaron la Guerra de Castas en el siglo XIX, hasta las más "aculturadas" poblaciones de la antigua región henequenera del noroccidente peninsular, pasando por las más tradicionales poblaciones del oriente y sur yucateco, donde el cultivo de la milpa aún es una actividad central en las economías familiares, los testimonios que dan cuenta de la existencia de estos pequeños seres sobrenaturales recopilados desde hace décadas por etnógrafos y folcloristas son una constante $^{1}$. Incluso en los núcleos urbanos más importantes de la Península, como Mérida, Campeche, Cancún o Valladolid, no es infrecuente toparse, de cuando en cuando, con notas periodísticas que recogen los testimonios de vecinos que dan cuenta de las "travesuras" que aterrorizan a los moradores de cierta vivienda, y que son adjudicadas a la presencia de los aluxó $o b^{2}$ en ellas. Tan populares resultan estos entes que, incluso en las dos tiendas de artesanías que posee el Gobierno del Estado de Yucatán en Mérida, es posible adquirir unos simpáticos muñecos de peluche antropomorfos que se ofertan como aluxes, los cuales vienen acompañados de la correspondiente etiqueta donde se explica al comprador que se trata de "los milenarios duendes del mayab".

1 Entre los folcloristas destacan los trabajos de D. Garrison Brinton, El folk-lore de Yucatán y R. Irigoyen, Esencia del folklore de Yucatán, quienes registran la pervivencia de diversas "supersticiones" entre los mayas, las cuales se traducen en las creencias en aluxo'ob y el balam, entre otros seres sobrenaturales, a los cuales catalogan como "fantasmas". Entre los trabajos de antropólogos que han registrado la presencia de estos seres en diversas regiones de la Península destacan A. Villa Rojas, Los elegidos de dios. Etnografía de los mayas de Quintana Roo, M. Gutiérrez Estévez, Mayas y "mayeros": Los antepasados como otros, E. Quintal, U lu'umil maaya wíiniko'ob: la tierra de los mayas, S. Terán y Ch. Rassmusen, La milpa de los mayas. La agricultura de los mayas prehispánicos y actuales en el noreste de Yucatán, M. Ruz, El Campeche maya: atisbos etnográficos y C. Chuc, Ts'ayatsil: el don de la reciprocidad entre los mayas contemporáneos, entre otros.

${ }^{2}$ El sufijo -óo $b$ se emplea en el idioma maya yucateco para indicar el plural. En el caso que nos ocupa, por ejemplo, alux sería el singular de aluxóob; por su parte, "aluxes" sería el plural castellanizado. 


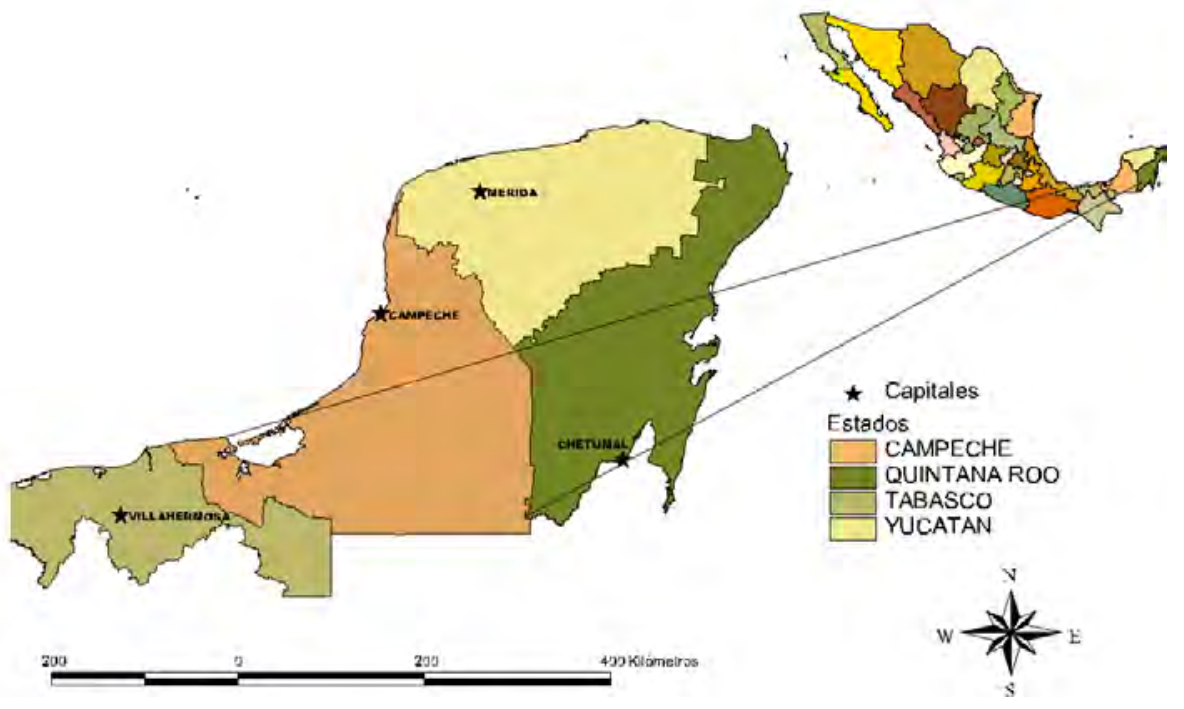

Mapa 1: La península de Yucatán y los tres estados que la conforman. Elaboración: Miguel Pinkus Rendón.

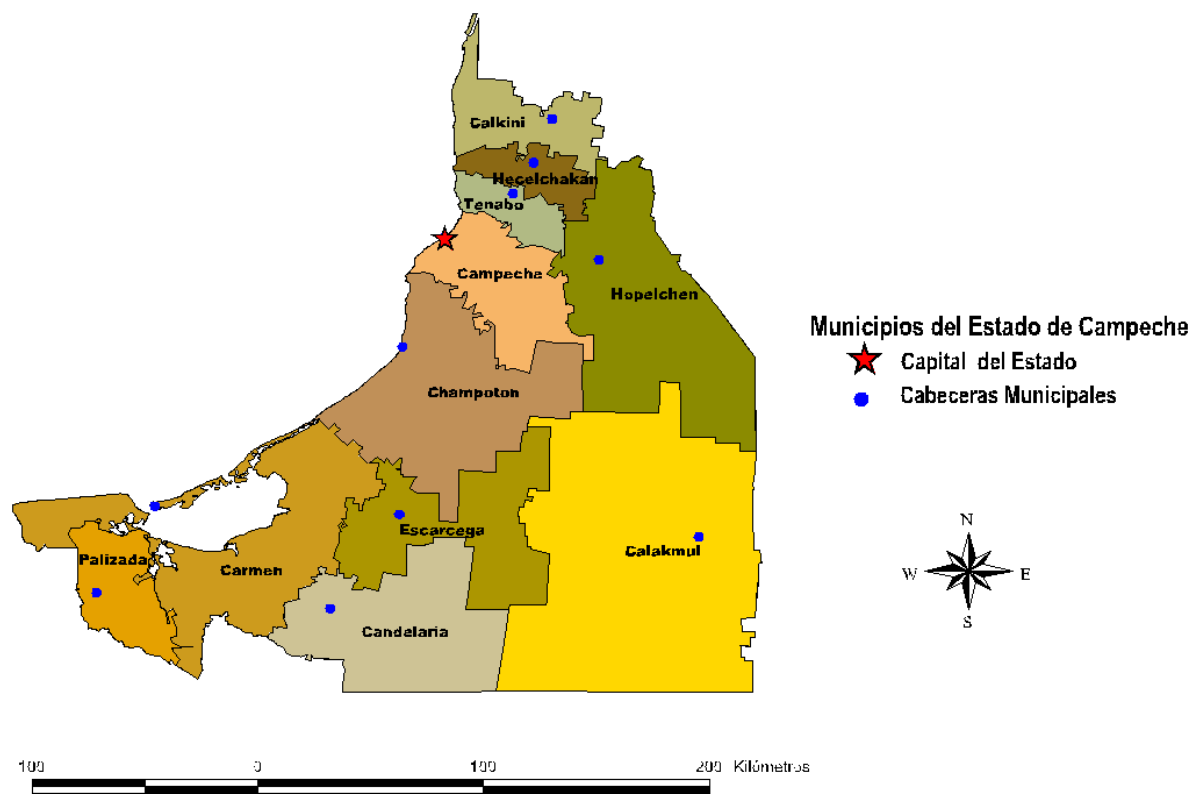

Mapa 2: Municipios del estado de Campeche. Calkiní, al norte, es donde se obtuvo la mayor parte de la información etnográfica para el presente trabajo. Elaboración: Miguel Pinkus Rendón. 
Pero más allá del proceso de folclorización que lo anterior ejemplifica, y que se ha venido aplicando sistemáticamente por parte de las élites gobernantes sobre diversos símbolos y rasgos culturales de los mayas peninsulares, ${ }^{3}$ con vista a apropiarse de ellos con fines mercantilistas y de reclamo turístico; la trascendencia y vigencia que poseen en el sistema cosmológico maya peninsular contemporáneo las entidades sobrenaturales que ahora me ocupan van mucho más allá de su mera faceta de suvenires. Tanto por su papel a la hora de configurar los espacios sagrados que permiten identificar los etnoterritorios que ocupan los mayas en nuestros días, ${ }^{4}$ como por su vinculación a la historia mítica de éstos espacios y de sus habitantes, así como por su categorización como "dueños" de los diversos ámbitos por los que transcurre la vida cotidiana de los seres humanos, la complejidad y el carácter multifacético que envuelve a los aluxó ob en el entramado cosmológico de los pueblos originarios peninsulares contemporáneos desborda por mucho los márgenes de una simple etiqueta adherida a un monigote de peluche que, eso sí, comparte con estos sagrados guardianes, dueños y paseantes del mayab algunos de sus rasgos externos más estandarizados por la tradición oral peninsular.

Como en el espacio disponible me sería imposible abarcar todas las particularidades que presentan en el ámbito peninsular ${ }^{5}$ los protagonistas de este escrito, para tratar de alcanzar el objetivo de esbozar algunos de los rasgos más significativos de su naturaleza sagrada, y con vistas a tratar de arrojar algo de luz sobre aquellos campos de la cosmovisión nativa en los que su presencia se hace más significativa, me centraré únicamente en algunas creen-

3 Dentro de este rubro podríamos incluir tanto diversos platillos de comida, bailes regionales, vestidos femeninos o hipiles y determinadas artesanías, que se ofertan por doquier en restaurantes, espacios públicos y tiendas ubicadas en el centro de las grandes ciudades peninsulares, como Mérida, Campeche o Valladolid. Todos ellos ofertados con la etiqueta de autenticidad de "lo maya", asegurando así al turista comprador una experiencia efímera con lo original y "exótico" de estas tierras. Para mayor información sobre estos procesos de folclorización, véase el trabajo de M. Pinkus, De la herencia a la enajenación. Danzas y bailes "tradicionales" de Yucatán.

4 Entendiendo los etnoterritorios como "el territorio histórico, cultural e identitario que cada grupo (etnolingüístico) reconoce como propio, ya que en él no sólo encuentra habitación, sustento y reproducción como grupo, sino también oportunidad de reproducir cultura y prácticas sociales a través del tiempo" (A. Barabas, Dones, dueños y santos. Ensayo sobre religiones en Oaxaca, p. 56).

5 Al referirme al ámbito peninsular me refiero a los tres estados que comparten la península de Yucatán, a saber: Campeche, Quintana Roo y Yucatán, en cuales habitan, en diferente proporción, los miembros de la etnia maya peninsular. 
cias y testimonios que he recabado en la población campechana de Nunkiní, y en otras cercanas a ésta como Tankuché o Calkiní. Lo anterior me permitirá mostrar cómo en estas comunidades de la región del Camino Real de Campeche, ${ }^{6}$ los aluxo'ob se erigen en uno de los principales símbolos sagrados supervivientes de la tradición cultural de matriz mesoamericana; pues en torno a ellos se originan la mayor parte de las prácticas rituales pertenecientes a este universo cultural, así como algunos elementos clave del complejo chamánico maya, y diversas creencias que condicionan la vida cotidiana de los individuos.

Cabe aclarar antes de comenzar, que los datos en los que basaré el siguiente trabajo forman parte de la tradición oral que en torno a los aluxes existe en las localidades ya mencionadas. Al respecto quisiera resaltar que son esencialmente dos las categorías de "conversaciones" (tsikbal) nativas que he empleado para la ocasión, ${ }^{7}$ por ser las que contienen la mayor parte de las informaciones relativas a las entidades que conforman el panteón maya peninsular en general, y a los aluxo'ob en particular. Así, en varios momentos emplearé datos extraídos de narraciones que pertenecen al género de las "historias o conversaciones antiguas" o uuchbéen tsikbalo'ob, las cuales remiten siempre a un pasado mítico muy lejano en el tiempo, y que, por ejemplo, hacen referencia a los orígenes del mundo, a las humanidades que lo habitaron anteriores a la actual, o a sucesos protagonizados por las entidades sagradas en aquellos tiempos remotos. El otro género de narraciones

6 Varios investigadores han propuesto la fragmentación de la Península en regiones o áreas culturales (M. Ruz, Los mayas peninsulares, idem, Los mayas ( $2^{a}$ parte) y E. Quintal, Solares, rumbos y pueblos: organización social de los mayas peninsulares, con subdivisiones internas en algunos casos. Éstas divisiones obedecen a las diversas características geográficas, poblacionales, económicas, sociopolíticas y culturales, así como a los divergentes procesos históricos que ha vivido la Península en su conjunto, lo que ha dado como fruto una cierta regionalización del espacio referido (M. Ruz, Los mayas ( $2^{a}$ parte)). Según Quintal, la población que habita la microrregión del Camino Real se caracteriza por tener en la agricultura de milpa, la horticultura, la producción de artesanías y el trabajo migratorio sus principales "estrategias de vida", amén de "conservar un elevado porcentaje de hablantes de lengua maya [...], y un apego especial a sus rituales y ceremonias ancestrales" (E. Quintal, Solares, rumbos y pueblos: organización social de los mayas peninsulares, p. 300).

7 La conversación es para los mayas un género de habla que está constituida por varios géneros narrativos (M. Gutiérrez, Mayas y "mayeros": Los antepasados como otros, p. 173). Para un análisis detallado de los diversos géneros narrativos que se dan entre los mayas peninsulares remito al lector a los trabajos de M. Gutiérrez Estévez, Mayas y "mayeros": Los antepasados como otros, F. Ligorred, Consideraciones sobre la literatura oral de los mayas modernos y F. Burns Una época de milagros. Literatura oral del maya yucateco. 
al que recurriré es el que se conoce bajo el nombre de "ejemplos" o "sucedidos", constituido por relatos que dan cuenta de acontecimientos mucho más recientes, protagonizados por individuos concretos, en muchos casos conocidos por una parte del auditorio que escucha las narraciones, y cuya presencia viene a reforzar la veracidad de los hechos que se refieren durante el relato.

\section{De la apariencia externa y la naturaleza intan- gible de los aluxo'ob}

A la hora de ofrecer una descripción del aspecto externo que presentan los aluxo'ob, es posible recurrir a un nutrido grupo de narraciones que ponen de manifiesto la frecuencia con que se dan los encuentros entre estas entidades y los humanos. Por comenzar enumerando sus rasgos físicos más representativos, quisiera ofrecer un testimonio que contiene lo que podríamos considerar una descripción paradigmática de los aluxo'ob, pues en él se conjugan buena parte de los rasgos que presentan estos seres en la tradición oral peninsular. Don Juan Cohuó, un milpero de 60 años habitante de Nunkiní, que en su infancia asegura haber sido visitado en varias ocasiones por tres de estos seres, me relataba con tranquilidad en una ocasión que "los aluxitos son chan personas, bajitos así; pequeñitos, como niños, pero están gordos. Están vestidos con su pantalón blanco y su camisa blancos. Pero no tienen sombrero. Su cara está arrugada y tienen granos, así. Pero hay que son más viejos, así". Complementando esta descripción, otro de mis interlocutores en Nunkiní, don Gilberto Chí, de 71 años, me remitió a un sucedido en el que un grupo de mujeres, entre las que se encontraba su madre, avistaron un alux cierta noche en la que se encontraban tejiendo en la puerta de una casa que daba hacia un terreno baldío:

Una vez mi mamá, vive ella donde está mi hermano, de noche vienen las vecinas... hacen tejido de guano así. Están allá... llegan como las 12 de la noche, y están haciendo tejido allá. Salió el alux en el terreno donde está ahora esa casa, y está cruzando así el terreno. Tiene su sombrerito, tiene sus zapatos de los antiguos, xtabixaná que le dicen, hasta su pantalón lo tiene puesto así (remangado por la rodilla), con su delantal. Y se cruzó aquí en el barrio corriendo, entro aquí, por donde está el doctor Sotelo porque eso es albarrada de antes, allá entró. Y dicen: mira ese 
chamaquito que se va. No es chamaquito, su cara está gastada. ¿Y qué es? es el alux. ¿Y qué tal si le tiramos? ¡Ja, tíralo para qué ves... ese te lleva allá, te enferma!.

Más allá de que lleven o no sombrero, en lo que coinciden la gran mayoría de los testimonios recopilados es en que los aluxó ob, además de tener estatura de niño y cara de adulto, visten como lo hacían "los antiguos", lo que resulta una primera prueba velada del origen mítico que se les supone ${ }^{8}$. Y es que, aunque en un par de relatos pude registrar la visión de aluxes que aparecieron desnudos, lo más habitual es que éstos lo hagan vestidos con camisa y pantalón blanco de manta, delantal de cotín, sabucán al hombro, sombrero de palma, y los tradicionales guaraches de henequén o tabixaná. En ocasiones incluso se menciona que hay quienes los han visto cargando una resortera (saats') o una carabina ( ts $^{\prime}$ oon), las cuales emplean para disparar a ciertos animales que, como ellos, son de puro viento y pululan por el monte, así como a los ladrones y a los animales depredadores que osan adentrarse en aquellas milpas que se encuentran bajo su protección con el fin de saquear sus frutos. La suma de todos estos elementos conformaba el atuendo tradicional de los campesinos mayas hasta hace más o menos tres décadas, ${ }^{9}$ cuando las prendas industrializadas y las modas occidentales se fueron imponiendo entre los más jóvenes por su fácil accesibilidad, menores costes y por erigirse en símbolos visibles de una modernidad superficial asociada con el progreso y unas mejores condiciones de vida que nunca acabaron de llegar a las comunidades.

Más allá del aspecto externo más o menos uniforme que suelen presentar los aluxóob en los diversos relatos que dan cuenta de sus encuentros

8 Se trata de rasgos que se repiten en las descripciones del alux en toda la región peninsular, indistintamente de que se añadan otros complementos a su atuendo o puedan ir acompañados de perros que, como ellos, también son de viento. En otras cosmovisiones nativas de Mesoamérica es frecuente encontrarse con seres sobrenaturales de estas características, denominados en muchos casos "duendes", los cuales reciben nombres como chaneques o la'a (en Oaxaca) (A. Barabas, Dones, dueños y santos. Ensayo sobre religiones en, p. 43), arux (chontales y mayas cruzo'ob) o wink-ir (chortís) (M. Ruz, Los mayas peninsulares).

9 Como bien ha apuntado Quintal en uno de sus trabajos, este atuendo era característicos entre los mayas que se dedicaban al cultivo de la milpa, siendo además un símbolo de su identidad, estando en la actualidad prácticamente desaparecido salvo "en quienes habitan ranchos y comisarias muy apartados en las regiones sur y oriente de Yucatán" (E. Quintal, Way yano'one: aquí estamos. La fuerza silenciosa de los mayas excluidos, p. 302). Actualmente los hombres visten ya prendas de algodón o poliéster de fabricación industrial, aunque mucho aún emplean sombreros y alpargatas. 
con los seres humanos, otra característica que se repite en todos los casos es su carácter intangible o inmaterial. En este sentido, todos los informantes con los que conversé acerca de estas entidades no dudaron en afirmar que éstas no son de carne y hueso como los hombres, sino que su composición es radicalmente diferente, pues son iik', "de puro viento", lo que provoca que sean invisibles la mayor parte del tiempo y para la gran mayoría de los seres humanos. Precisamente esta naturaleza incorpórea e invisible es la primera característica efectiva que permite reconocer a los aluxo'ob como entidades sagradas, ${ }^{10} \mathrm{y}$ asemejarlos con otros númenes que pueblan el panteón maya peninsular, indistintamente del origen histórico o adscripción cultural que puedan tener. Asimismo, la composición iik' (o de viento) de los aluxes resulta ser uno de los orígenes de su "peligrosidad" hacia los seres humanos, pues en su cotidiano deambular por montes, milpas y calles dejan tras de sí una estela de aires (también invisibles) que, al entrar en contacto con cualquier desafortunada persona que fortuitamente pueda llegar a cruzarse en su camino, acaban por enfermarla provocándole dolores de cabeza y calentura. ${ }^{11}$ Para paliar estos síntomas, las personas deberán visitar a alguno de los especialistas rituales nativos o jmeeno' ob que actualmente "trabajan" en sus comunidades para que los santigüen y extraigan el mal aire del interior de sus cuerpos. Cabe subrayar que en estos casos, la relación que se da entre el alux y la enfermedad no se considera que derive de una acción voluntaria por parte de aquel, lo que implica que no se les etiquete como entidades maléficas o kakaxbaal, tal y como sí sucede con otros seres "de viento" como el Ual pach o la Xtabay, en cuya naturaleza sí está "espantar" y provocar enfermedades a las personas que se cruzan en su camino, siendo por ello identificadas con el ámbito del Kisín, el diablo maya yucateco. ${ }^{12}$

${ }^{10}$ Lo sagrado siempre es visto como algo extraordinario, opuesto a lo ordinario que es el campo de lo humano. Valga aquí la acepción propuesta por M. Bartolomé, en el sentido de que lo sagrado "manifiesta aspectos diferenciados del mundo ordinario y que aparecen revestidos de una carga o potencia de la que carecen otros aspectos de la realidad” (M. Bartolomé, La dinámica social de los mayas de Yucatán. Pasado y presente de la situación colonial, p. 99-100).

${ }^{11}$ Conviene apuntar que las entidades "sagradas" son vistas en muchas culturas, y también en la maya, con una cierta carga de peligro y temor por parte de los humanos en función del "poder" que atesora, el cual muchas veces se revela incontrolable para ellos. Al respecto R. Otto hacía hincapié en este carácter dual positivo-negativo de lo sagrado, mencionando que uno de los primeros medios de expresarlo fue como "lo terrible, lo espantable, lo pavoroso en sentido "natural" (R. Otto, Lo santo. Lo racional y lo irracional en la idea de Dios, p. 89).

${ }^{12}$ Aunque vistas en muchos casos como maléficas, estas entidades suelen tener entre sus víc- 


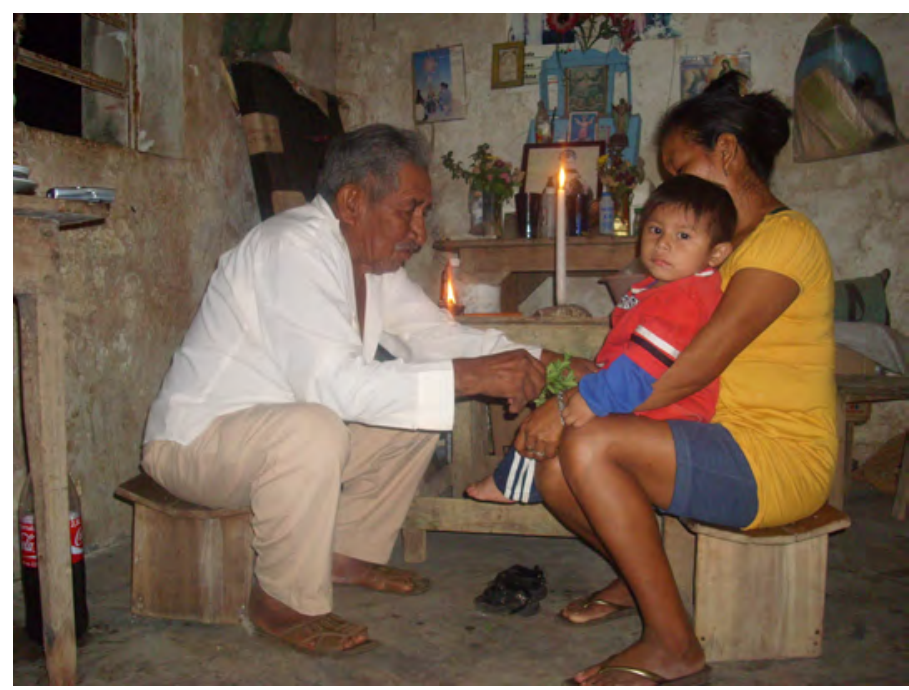

Imagen 1: Un jmeen o especialista ritual del pueblo de Nunkiní, Campeche, santigua a un niño para extraerle un aire alojado en su interior. Fotografía del autor.

Sin embargo, este carácter volátil e invisible que la mayor parte del tiempo adoptan los aluxo'ob se quebranta en determinadas ocasiones, permitiendo que ciertas personas en circunstancias especiales puedan verlos e incluso interactuar con ellos. Los casos paradigmáticos los encontramos, sobre todo, entre los niños, especialmente los varones menores de 8 años. Tal es la creencia sobre la preferencia que sienten los aluxo'ob por "jugar" con ellos que varios informantes aseguraron que, hasta hace algunos años, las madres de Nunkiní aún mantenían la costumbre de vestir con hipiles a sus hijos, tratando así de confundir a los aluxo'ob y evitar que éstos visitaran a sus vástagos causándoles enfermedades derivadas de su condición "fuerte”. Quizá por hallarse aún en el proceso de socialización primaria, y por ello ser aún mayeros "no contaminados" por la aculturación nacionalista y occidentalizante del sistema educativo obligatorio y público del estado mexicano, los infantes son quienes con mayor frecuencia mantienen encuentros con los aluxo'ob en los solares domésticos, mientras juegan despreocupadamente alejados de las

timas a quienes incumplen ciertos preceptos morales de la comunidad o se alejan de las prácticas tradicionales, y por tanto su acción también podría considerarse benéfica en tanto que garante de un orden social tradicional. Esta ambigüedad ética de lo sagrado es una característica muy extendida en las cosmovisiones mesoamericanas (A. Barabas, Dones, dueños y santos. Ensayo sobre religiones en Oaxaca, p. 48). 
miradas de sus progenitores. Los testimonios recopilados al respecto son numerosos, y ofrecen dos explicaciones al respecto. La más frecuente es que los padres de los niños que sufren las visitas del alux se atrasaron en la realización de alguno de los rituales de ofrendas que se les dedican a estos "dueños" originarios de los terrenos. Así, la materialización del alux y la enfermedad que esto acarrea a los niños que son objeto de esta visita, se interpreta en muchos casos como una suerte de recordatorio dirigido a los adultos para que éstos restablezcan los vínculos de reciprocidad que han de regir las relaciones entre los hombres y las añejas potencias sobrenaturales de los espacios, mediante la oportuna entrega de los alimentos y bebidas que marca la tradición, amén de tabaco, incienso y veladoras, sustentos por antonomasia de lo sagrado en las culturas mesoamericanas.

La enfermedad de un hijo, del propio cabeza de familia o de los animales que viven en los solares de la vivienda, suelen ser el último eslabón de las acciones que acometen los aluxóo ob en contra de quienes, por omisión u olvido, incumplen con sus obligaciones de retribuirles a ellos, las entidades sagradas que señorean sobre los diversos espacios de la naturaleza, una parte de los beneficios que obtuvieron de las actividades productivas que desarrollaron en ellos. Previo a este paso, los relatos ilustran múltiples formas en que los alu$x o^{\prime} o b$ se hacen presentes y buscan llamar la atención de los infractores para que éstos se apresuren a restablecer la reciprocidad ritual, y con ella el orden social. Silbidos prologados en las noches, desaparición de herramientas de trabajo, golpes en puertas y techos de las viviendas, accidentes reiterados en la milpa, el hallazgo constante de serpientes, o la repentina enfermedad y muerte de los animales que se crían en solares y ranchos, son sólo algunos de los casos que me fueron referidos por mis interlocutores, después de haberlos vivido en primera persona, para ilustrar las formas que emplean los aluxes para reclamar y castigar a aquellos que incumplieron el pacto mítico de reciprocidad entre hombres y potencias de la naturaleza. Los relatos que dan cuenta de estos episodios son tan numerosos como estandarizados, y pertenecen al género de los "sucedidos ejemplares", pues ilustran con todo lujo de detalles los males que padecieron quienes, con sus actos u omisiones, osaron atentar contra el orden sagrado que sustenta el correcto funcionar de la vida y la sociedad maya. 


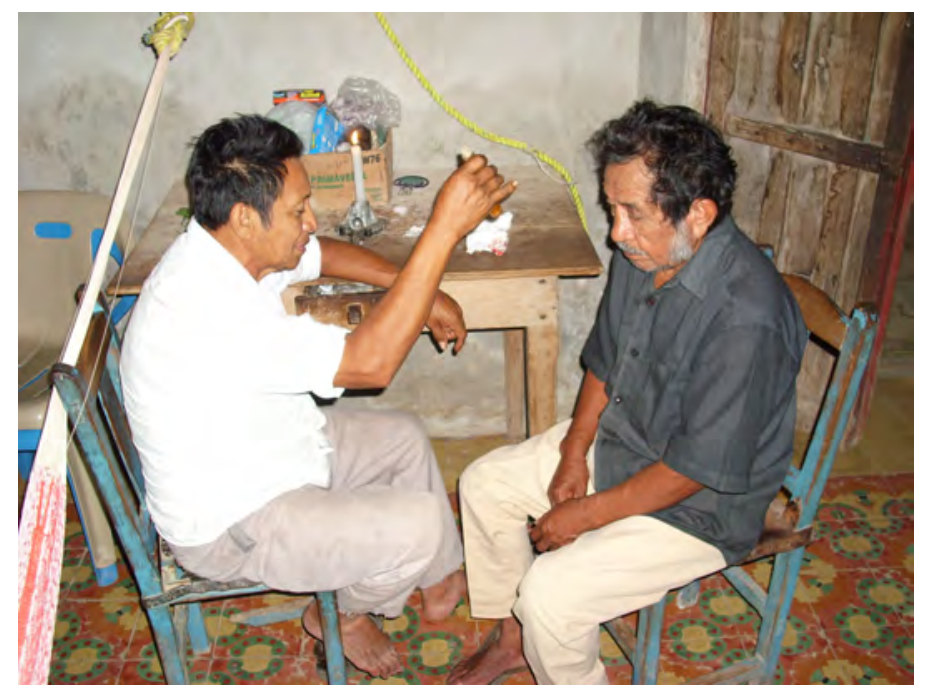

Imagen 2: Un jmeen realiza una curación en el poblado de Nunkiní, Campeche.

\section{Orígenes míticos de los aluxo'ob y sus atribu- ciones actuales}

Una vez que he delineado los rasgos esenciales del aspecto y la naturaleza de los aluxes, voy a tratar ahora de fijar el origen que se les supone, y como éste determina los espacios que ocupan en la actualidad, algunas de sus atribuciones y, finalmente, el protagonismo que desempeñan en el mantenimiento de una parte importante del sistema cosmológico de tradición mesoamericana por parte de los mayas peninsulares. A diferencia de los datos referidos hasta aquí, extraídos de "sucedidos" y "ejemplos" en los que mis propios informantes se erigían en garantes de la veracidad de los relatos al ser ellos, algún familiar o conocido suyo los protagonistas, las narraciones que dan cuenta sobre el origen mítico de los aluxo'ob se encuadran dentro del género de las "conversaciones antiguas" o uuchbéen tsikbalo'ob, las cuales remiten a un pasado local de carácter mítico y oscuro en el que acontecieron, por ejemplo, las sucesivas creaciones y destrucciones del mundo y sus pobladores. Se trata de historias que han sido transmitidas de generación en generación, y cuya veracidad radica precisamente en la propia supervivencia del relato a través del tiempo. Es en esta clase de narraciones, rodeadas siempre de cierto halo de secretismo, donde se menciona que los aluxo'ob fueron "las primeras 
personas" que poblaron la tierra; que ellos fueron quienes construyeron las pirámides y los templos que hoy se encuentran, en muchos casos, sepultados bajo los montículos de piedras (denominados kaká o cuyos) que salpican el paisaje peninsular, dentro de los cuales quedaron "encantados" y "sólo en espíritu” después del gran diluvio que anegó la tierra y acabó con esa primera humanidad, tras la que seguirían la de "los antiguos mayas" y la actual. Así resumía estos sucesos don Juan, una noche mientras conversábamos plácidamente en su solar:

pues sí, ese alux es primer personas. Así dicen, que fueron las primeras personas ellos. Que hubo como un encantamiento así, que ellos quedaron así como están ahora, sólo espíritu, así, cuidando los terrenos en los montes. Hubo como un diluvio y ellos hicieron sus casas debajo de los kaká entonces. Están allá. Hicieron su casa y luego lo taparon con piedra para que no le entra el agua... pero el agua llegó casi al cielo. Entonces... cuántos años que tarda para que baja el agua... que cuando ya está (se secó), entonces ya se murió, así, no más el espíritu de esas personas quedó, como está ahorita, encantados en el cuyo.

En otros relatos, por el contrario, la autoría de los cuyos $^{13}$ recae en otros personajes míticos del pasado, íntimamente relacionado con los aluxóob, denominados $p^{\prime} u$ uso'ob, a quienes algunos de mis interlocutores calificaron como "los padres de los aluxitos". Eran éstos unos seres de pequeña estatura y corcovados, dotados de enormes poderes mágicos que les permitían, entre otras cosas, tallar y mover con suma facilidad piedras de gran tamaño. Así se explica que pudieran construir los grandes edificios que hoy en día se pueden contemplar en los sitios arqueológicos. Previo a la llegada del diluvio y la posterior desaparición de esta primera humanidad, estos enanos corcovados encargaron a los aluxo'ob el resguardo de los palacios y templos que habían construido y colmado de tesoros, los cuales fueron cubiertos de piedras para evitar así su saqueo. Según don Felipe Naal, otro campesino de Nunkiní, fue de esa forma que los protagonistas de este escrito quedaron confinados hasta nuestros días a vivir bajo los cuyos o kaká, con la encomienda de proteger

${ }^{13}$ Los cuyos, kakáo'ob o muulóob son los nombres que reciben en la actualidad los montículos de piedras cubiertos de vegetación que salpican la planicie yucateca y que corresponden a antiguas y derruidas construcciones prehispánicas. 
"los restos de los antiguos". Bajo estas aglomeraciones de piedra se encuentran, según don Felipe:

sus casitas de piedra labrada de los aluxitos, allá están así. Y todo lo que tenemos nosotros aquí: tenemos vasos, tenemos mesas, sillas, todo así, también tienen los aluxes; pero puro de piedra está todo abajo del cuyo. Si lo llegamos a ver, tenemos televisión, tenemos como el estéreo, todo eso lo tienen abajo de la tierra en sus casas, si escarbamos el cuyo sacamos todo eso que es de ellos, de los antiguos.

Más allá de la modernidad que en forma de bienes de prestigio propios de la cultura occidental ha venido colonizando hasta los mundos virtuales de los mayas peninsulares representados en las viviendas de los aluxo'ob ubicadas en el interior de los cuyos, la presencia de estas entidades entre los restos del pasado se hace patente de muy diversas formas en nuestros días, condicionando parte de la vida cotidiana de los actores sociales. No en vano, en las poblaciones del Camino Real de Campeche, uno de los nombres que reciben los aluxo'ob es el de Yumlikaká, que se puede traducir como "dueños" o "señores” de los cuyos. Su presencia en el interior de los montículos de piedra hace que éstos puedan ser vistos como lugares sagrados y, por ende, peligrosos. ${ }^{14}$ Así lo demuestran los cientos de relatos que sobre las ruinas existen en la tradición oral peninsular, los cuales dan cuenta de los riesgos que acechan a los hombres que se acercan a estos lugares sin el debido respeto, con ánimo de lucro, o en determinadas horas y días señalados como "peligrosos".

\footnotetext{
${ }^{14}$ Como atinadamente señaló Manuel Gutiérrez Estévez, el poder de los cuyos se manifiesta en sus múltiples niveles de significación. Temporalmente conectan el pasado con el presente. Espacialmente crean un espacio único, pues no son el espacio habitado por los hombres pero sí son habitados por los "dueños"; pueden estar en los montes, milpas y solares, pero no son ninguno de estos espacios. Se trata del "espacio del margen, el escenario de las experiencias extraordinarias", y por ello, para los mayas peninsulares son "el espacio sagrado por antonomasia” (M. Gutiérrez Estévez, Mayas y “mayeros”: Los antepasados como otros, p. 437).
} 


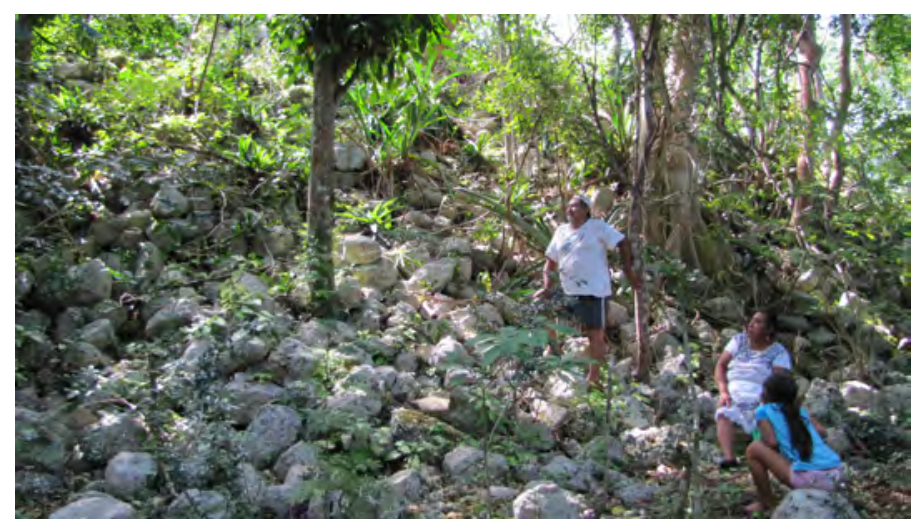

Imagen 3: Imagen de un cuyo o kaká en el ejido de Nunkiní, Campeche. Fotografía del autor.

De esta forma, cualquier maya peninsular sabe que al deambular por las inmediaciones de uno de estos montículos a medio día, a media noche, en viernes santo o durante el Carnaval, se arriesga a sufrir el encuentro con algún "espanto" o ser afectado por alguno de los vientos invisibles que salen de su interior, lo que en cualquier caso le hará perder la salud y enfermarse de gravedad. También son recurrentes las narraciones de personas que cayeron enfermas de gravedad, llegando incluso morir, cuando trataron de penetrar en los montículos en busca de las riquezas que "los antiguos" depositaron en su interior. La codicia y el deseo de riquezas materiales, características siempre asociadas a la naturaleza de los $t s^{\prime} u u l e s,{ }^{15}$ siempre ha sido motivo de infortunio entre los mayas.

Sin embargo, como suele ser habitual en los ámbitos y seres que pueblan las cosmologías mesoamericanas, la dualidad benéfico-maligna está muy presente en la percepción que las personas tienen sobre estos espacios sagrados, y por ende ambivalentes, en los que se conectan pasado y presente. Por ello, además del peligro inherente que representan para los humanos por su condición diversa y "poderosa", los montículos bajo los que los que se hallan los restos del pasado y sus moradores/guardianes se vislumbran hoy como

${ }_{15}$ El término $t s^{\prime} u u l$ o "extranjero" fue el que emplearon los mayas desde el inicio de la conquista para designar a los españoles. Con el tiempo se empleo para designar a los miembros de "la etnia dominante", los patrones de las haciendas y los blancos que residían en las ciudades peninsulares, siendo sus principales características ser "patrones, poderosos, blancos, ricos y tienen "buenos apellidos” (E. Quintal, Way yano' one: aquí estamos. La fuerza silenciosa de los mayas excluidos, p. 312). 
símbolos fundamentales, que permiten a los miembros de la etnia maya peninsular apropiarse, delimitar y dotar de significados propios a aquellos territorios donde transcurren sus vidas. En la comunidad de Nunkiní este proceso se ejemplifica en la inclusión de los aluxo'ob en la heterogénea categoría de Yumtsilo'ob o "dueños" de la naturaleza (bosques, animales, vientos, cenotes), herederos de las antiguas deidades precolombinas que antaño señoreaban sobre los diferentes ámbitos por los que transcurría la vida humana. ${ }^{16}$

Aunque en la actualidad estos Yumtsilo'ob han visto reducida tanto su variedad como algunos de sus tradicionales campos de actuación, debiendo ceder parte de sus dominios y atribuciones a las deidades del panteón católico que llegaron a imponerse desde Europa (las cuales asumieron no sólo los dominios, sino varias de las características de los añejos "dueños" mayas), todavía hoy conservan parte de su añeja influencia sobre las diversas actividades productivas que se desarrollan en los bosques y selvas que rodean las poblaciones indígenas. Dicha influencia deriva, en el caso de las comunidades del municipio de Calkiní que nos ocupan, de la gran abundancia de cuyos que existen en el entorno, fruto de la alta densidad demográfica que existía en esta región en época prehispánica ${ }^{17}$. En este sentido, casi cualquier vecino de Nunkiní es capaz de ubicar entre veinte cuyos diferentes, cada uno con su respectivo nombre, situados tanto en los montes donde muchos realizan sus milpas, siembran sus huertos de hortalizas, crían unas pocas cabezas de ganado o practican la caza, como dentro de la misma población, junto o en el interior de los solares domésticos. Lo anterior provoca que las entidades sobrenaturales que residen bajo las ruinas deban ser tenidas en consideración, tanto a la hora de sembrar y cosechar los productos de la milpa, como a la hora de habitar una vivienda, ir a "tirar" (o cazar) un venado o cosechar miel de las colmenas.

${ }^{16}$ Según Villa Rojas el término Yumtsilo’ob se traduce como "señores” o "patrones” e identifica al conglomerado de "dioses y espíritus paganos" relacionados con la agricultura, mismo que al autor divide en tres grupos en función de sus atributos y funciones particulares: balamo'ob (vigilantes y protectores de milpas, pueblos y hombres), los kuilo'ob kaaxo'ob (vigilantes y protectores de los montes) y chaco'ob (manejan las lluvias y reparten lluvias) (A. Villa Rojas, Los elegidos de dios. Etnografía de los mayas de Quintana Roo, p. 288). Para Quintal los Yumtsilo'ob son los "dueños" encargados de cuidar los diferentes espacios sagrados que existen en la cosmovisión maya (cuevas, cenotes, grutas, cuyos); son incorpóreos o de "puro viento", sin embargo, en ocasiones, se dejan ver transformados en Aluxo'ob (duendes), P'uuso'ob (jorobados) o Kukuch p'óoko'ob (sombrerotes) (E. Quintal, U lu' umil maaya wíiniko'ob: la tierra de los mayas).

${ }^{17}$ Sobre la alta densidad de población de la península de Yucatán a la llegada de los españoles véase A. Benavides, Geografía Política de Campeche en el siglo XVI. 
La profusa presencia que tienen los aluxo'ob y otros "dueños" originarios de los espacios que habitan o trabajan los humanos, tales como los balam $k a^{\prime} a x$, se deja entrever en la vigencia que mantienen los rituales de ofrendas que se les dedican. Así, resulta muy extraño encontrar a una sola familia que al menos una vez al año no realice una ceremonia de ukli solar o "bebida de solar", aunque ninguno de sus miembros se dedique ya a la agricultura. Para esta sencilla celebración, la familia que ocupa una vivienda contrata los servicios de alguno de los jmeenó $o b$ o especialistas rituales locales para que, en su nombre, invoquen a los aluxó ob que moran en los cuyos de los alrededores y les ofrenden saka', una bebida elaborada a base de maíz nuevo, cocido sin cal, al que se añade miel y cacao. La justificación que ofrecen los oficiantes, profesionistas en muchos casos, es que sus actuales casas se levantaron sobre terrenos que antiguamente pertenecieron a los aluxitos, y por tanto es su obligación "darles su bebida una vez al año como agradecimiento porque nos dejan vivirlo". Por todos es sabido que, en caso de faltar a este compromiso, los agraviados dueños sobrenaturales del espacio les recordarán sus obligaciones mediante el envío de una enfermedad al habitante más débil del hogar, misma que podría derivar en su muerte en caso de no consumarse a tiempo la ofrenda.

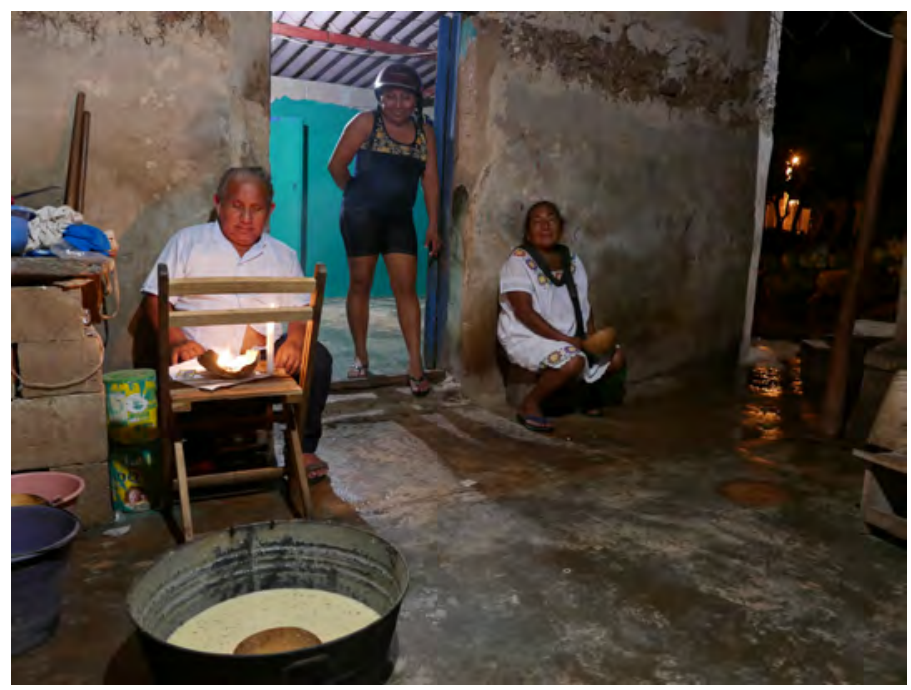

Imagen 4: Un especialista ritual o jmeen ante la bebida de maíz o saka' destinada a ofrendar a los "dueños" del terreno o yumtsilo'ob en Nunkiní, Campeche. Fotografía del autor. 
Los campesinos, por su parte, suelen ser mucho más conscientes de la importancia de agradecer en tiempo y forma a los aluxo'ob, en sus diferentes acepciones de j-xíimbal k'áaxo'ob (caminantes de los montes) y j-kalan $k^{\prime}$ áaxo'ob (cuidadores de los montes), por todos los productos que han obtenido de trabajar una tierra que, en origen, no es propiedad de los seres humanos, sino que, tal y como me decía un campesino de Tankuché, "no más estamos de prestado y por eso tenemos que regresar una parte de lo que sacamos". Por ello, sin llegar a igualar el extenso corpus de rituales que aún mantienen los mayas de la más tradicional región maicera del oriente peninsular, ${ }^{18}$ los campesinos de mayor edad, más apegados a las antiguas prácticas, acostumbran a realizar al menos dos rituales de ofrendas al año dirigidas tanto a los aluxo'ob como a los balam $k^{\prime} a a x o^{\prime} o b$, cada una en un momento particular del proceso productivo. Al menos uno de estos rituales tiene lugar en el solar de la vivienda familiar, mientras que el o los otros se llevan a cabo en la parcela donde se cultiva. Lo más habitual es que se realice una pequeña ofrenda antes de iniciar los trabajos de preparación del suelo, otra antes de la siembra y la última (y más copiosa) una vez que se han recolectado los primeros frutos de la cosecha. Por su complejidad y volumen, esta última será dirigida la mayoría de las veces por un jmeen contratado ex profeso por la ocasión. De esta forma, los campesinos se aseguran de tener a los aluxó ob como aliados y protectores, favoreciendo así la producción de los cultivos e impidiendo que en su ausencia ladrones o animales depredadores puedan irrumpir en ellos y saquear sus frutos.

Las creencias que en estas páginas apenas estoy esbozando, para los mayas toman cuerpo en decenas de relatos que, contados en forma de "sucedidos", remiten detalladamente a casos de campesinos que cultivaron sus terrenos sin ofrendar nada a cambio a sus dueños originarios. Los protagonistas de dichos sucedidos sufrieron toda clase males en forma de accidentes con las herramientas de labranza, ramas o palos secos que se les clavaban en sus pies semidesnudos, caídas reiteradas, culebras venenosas que los acechan a cada rato, o frecuentes dolores y molestias al regresar a sus casas luego del trabajo en sus milpas. En todos los casos la solución siempre llega tras la visita a un jmeen, quien tras consultar su saastún o piedra traslúcida, confirma que

${ }^{18}$ Sobre el complejo ciclo ritual relacionado con el cultivo de la milpa que siguen los mayas milperos del oriente peninsular, consúltese el acuciante estudio realizado por Silvia Terán y Christian Rasmussen en la población de Xocén, Yucatán (S. Terán y Ch. Rasmussen, Xocen, el pueblo en el centro del mundo). 
todos los males derivan del enojo de los "dueños" del terreno ante la avaricia mostrada por los hombres que no les retribuyeron por los bienes obtenidos, rompiendo así la cadena de intercambios que sustenta la relación entre hombres y deidades desde tiempos inmemoriales. Todo se soluciona cuando el campesino conoce la causa de sus males y realiza con la ayuda del jmeen el ritual más complejo de los que se dan en esta región, denominado janli kool o comida de milpa, con el fin de "agradecer a los dueños y regresar algo de lo que nos da el terreno". En este ágape ritual, destinado a los númenes de la naturaleza que moran bajo los cuyos, además de una bebida de maíz nuevo, cacao y endulzado con miel o azúcar denominada saka', las familias ofrecen dos guisos exclusivos de esta celebración, denominados tuch y kool respectivamente, ambos fuertemente condimentados y elaborados con la carne de un pavo que es sacrificado por el especialista ritual para la ocasión y a base de maíz, así como 13 pibes de frijol y pepita de calabaza, ${ }^{19}$ cuatro cigarros (preferentemente sin filtro), pom, ${ }^{20}$ varias veladoras y grandes cantidades de trago, ingredientes en su mayoría de origen mesoamericano para saciar el apetito de las añejas potencias de estas tierras.

${ }^{19}$ Los pibes son una especie de panes circulares elaborados de masa de maíz, y cocidos en hornos subterráneos. En el caso de los que se elaboran para este ritual están conformados de siete capas, en las que se alternan crema de frijol y de pepita de calabaza. Maíz, frijol y calabaza son tres de los productos habituales en las milpas o sembradíos de los mayas y del resto de indígenas mesoamericanos.

${ }^{20} \mathrm{El}$ pom es la resina de un árbol muy aromatizante, la cual se quema durante el ritual, proporcionando abundante humo y un fuerte olor. Su uso es parte fundamental en todos los rituales de ofrenda a las entidades sagradas, tanto las de origen mesoamericano como a los santos y cruces. 


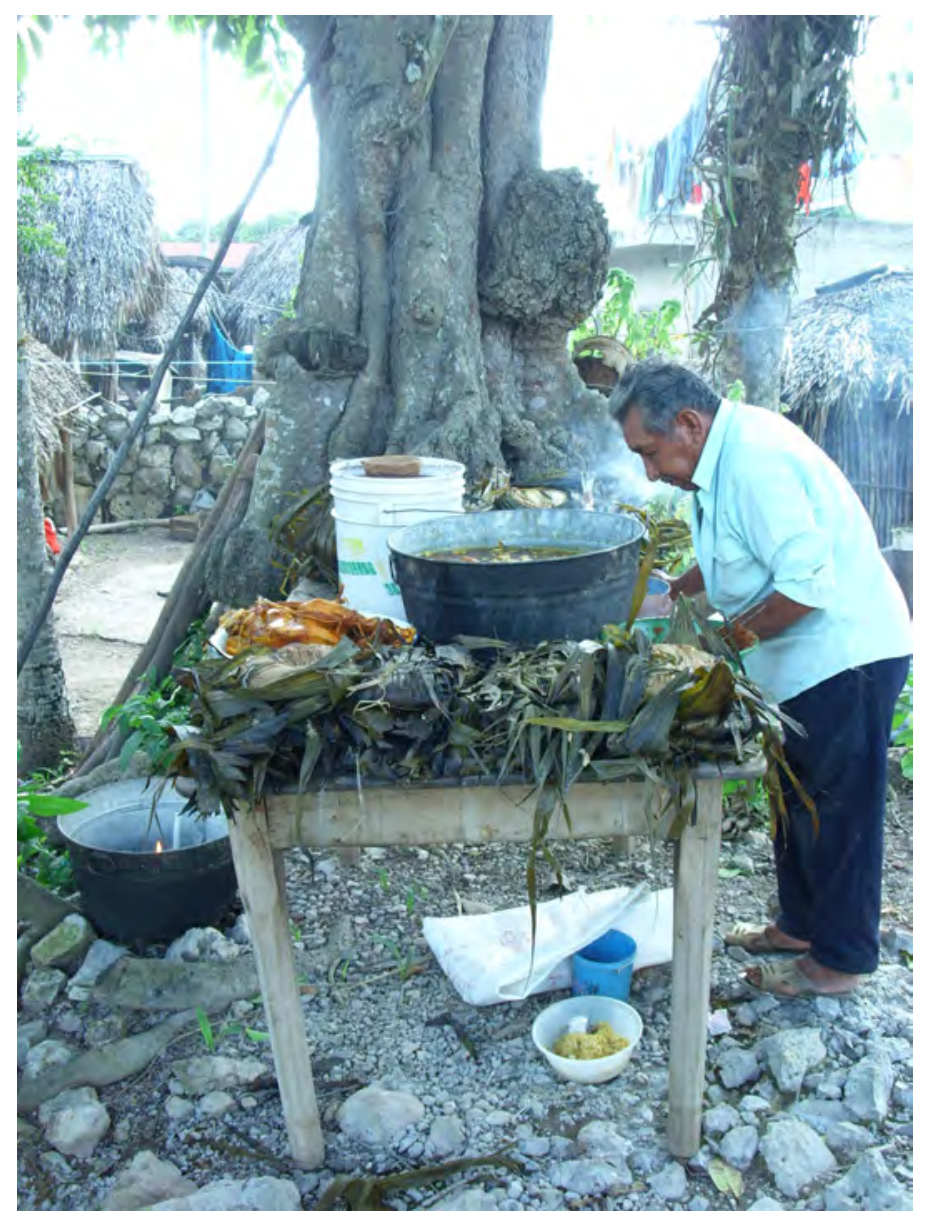

Imagen 5: Entrega de las ofrendas de comida durante un ritual de janli kool en Nunkiní, Campeche. Fotografía del autor.

\section{Colofón: no todo ha sido dicho aún}

Aunado al hecho de que agricultores, ganaderos, cazadores y apicultores les ofrenden y reverencien buscando así contar con su protección (para ellos y sus familiares) y alcanzar el éxito en las tareas productivas que desempeñen, los aluxo'ob y los espacios donde moran estas entidades se encuentran íntimamente ligados al complejo chamánico de los mayas peninsulares. Así lo demuestra, por ejemplo, el hecho de que el saastún, la piedra transparente que constituye el símbolo del poder de los especialistas rituales locales o jmeen, se localice casi siempre en las inmediaciones de los cuyos y les sea en- 
tregada únicamente a aquellas personas que nacen con el don de establecer comunicación con los aluxo'ob y otras entidades poderosas. Previamente a la obtención de estas piedras traslúcidas, donde los especialistas rituales verán los mensajes enviados los númenes, y durante el resto de sus vidas, los elegidos para convertirse en jmeen tendrán diversas experiencias oníricas en las que serán transportados al interior de los cuyos. Será allí donde entrarán en contacto con sus moradores, quienes les iniciarán en los complejos conocimientos de los rezos y rituales que les permitirán llevar a cabo las diferentes ceremonias de curación y ofrendas que habrán de conocer, con vistas a ejercer exitosamente como los únicos intermediarios culturalmente reconocidos entre los hombres y las deidades.

La relación que desde la infancia establecen quienes están predestinados a convertirse en jmeen y los aluxóob en base a la piedra de poder, se condensa a la perfección en las palabras que en una ocasión me dijo don Gonzalo, uno de los especialistas rituales con quien tuve la suerte de trabajar en Nunkiní, cuando mencionaba que: "sólo en los cuyos se encuentran porque es el dueño del cuyo quien lo guarda allá el saastún... para que sepa yo cómo le tengo que entregar su comida; cómo es su rezo, cómo es que le gusta, así, y no lo vaya a rechazar cuando yo lo voy a hacer". El ayudante, o itzá, de este jmeen me ampliaba la información asegurándome que: "allí dentro (del saastún) ven lo que les dicen los dueños. Se comunica con ellos por esa piedra, así. Pero no más ellos pueden ver qué les están diciendo por los aluxitos y por los balames; cualquiera no ve nada allá, sólo ellos que tienen ese don para ver". De esta forma, el saastún se convierte en el símbolo del poder que poseen los $h$-menó ob para mantener comunicación continua con los aluxó ob, quienes se encargan de instruirlos en los secretos de su oficio. Secretos que en forma de diversos y complejos rezos, conocimientos herbolarios, les permitirán realizar con éxito, además de las ofrendas que los humanos dedican a los "dueños", las curaciones que frecuentemente les son requeridas por sus vecinos. ${ }^{21}$

Por tanto, en nuestros días, los aluxóob se erigen también en guardianes del alto conocimiento esotérico acumulado durante milenios por los antiguos sacerdotes mayas, siendo los encargados de transmitirlo a quienes, en

${ }^{21}$ Como han subrayado diversos autores como M. A. Bartolomé, en la concepción maya la enfermedad se entiende como "un castigo por una falta o violación al código transaccional que rige las relaciones del individuo tanto con su comunidad como con la naturaleza”; dicho castigo ha de entender como un "llamado al orden" realizado por las potencias de "carácter sobrenatural" que actúan como vigilantes del sistema cultural (M. Bartolomé, La dinámica social de los mayas de Yucatán. Pasado y presente de la situación colonial, p. 243). 
función de su "don", son capaces de comunicarse con ellos y adquieren la obligación de perpetuarlo. Una característica más que añadir al quehacer de estas entidades multifacéticas y de indiscutible carácter sacro que, encarnando el pasado ancestral lo reactualizan y tonifican con su actuar cotidiano en el presente. Símbolos de una particular concepción sagrada del territorio, la naturaleza y sus habitantes; garantes del mantenimiento de las relaciones sustentadas en la ética del don entre hombres y entidades poderosas a través de los rituales periódicos que aquellos les dedican, ${ }^{22}$ los aluxóo $b$ se presentan como una atalaya desde donde corroborar la vigencia que tiene la matriz cultural mesoamericana en la cosmología maya peninsular actual, a pesar de la vorágine de cambios e imposiciones que se ciernen sobre las poblaciones originarias de la península de Yucatán.

\section{Bibliografía citada}

1. Barabas, Alicia M., Dones, dueños y santos. Ensayo sobre religiones en Oaxaca, México, Instituto Nacional de Antropología e Historia, Grupo Editorial Miguel Ángel Porrúa, 2006.

2. BArtolomé, Miguel Alberto, La dinámica social de los mayas de Yucatán. Pasado y presente de la situación colonial, México, Instituto Nacional Indigenista, 1988, 343 págs.

3. Benavides C., Antonio, Geografía Política de Campeche en el siglo XVI, México, Instituto Nacional de Antropología e Historia, 1991.

4. Burns, Allan F., Una época de milagros. Literatura oral del maya yucateco, Mérida, Universidad Autónoma de Yucatán, 1995.

5. Chuc Uc, Cessia Esther, Ts'ayatsil: el don de la reciprocidad entre los mayas contemporáneos, Campeche, Universidad Autónoma de Campeche, 2008 .

6. Garrison Brinton, Daniel, El folk-lore de Yucatán, Mérida, Gobierno del Estado de Yucatán, 1976 (1937, $1^{\text {a }}$ edic.).

${ }^{22} \mathrm{Al}$ aludir a la ética del don me estoy refiriendo al "conjunto de concepciones, valores y estipulaciones que regulan las relaciones de reciprocidad entre [...] los humanos y lo sagrado", cuyo estricto cumplimiento permite "mantener buenas relaciones con los otros y los númenes; donar respeto y ofrenda y obtener a cambio el equilibrio del cosmos, la salud y la abundancia” (A. Barabas, Dones, dueños y santos. Ensayo sobre religiones en Oaxaca, p. 55). 
7. Gutiérrez Estévez, Manuel, "Cuento, ejemplo y conversación entre los mayas de Yucatán”, en Ethnica núm. 18 (2), Madrid, Centro Superior de Investigaciones Científicas, 1982, pp. 93-116.

8. Gutiérrez Estévez, Manuel, "Mayas y "mayeros": Los antepasados como otros", en De palabra y obra en el Nuevo Mundo. 1.- Imágenes Interétnicas, Miguel León-Portilla, M. Gutiérrez Estévez, Gary H. Gossen y J. Jorge Klor de Alva (eds.), Madrid, Junta de Extremadura, Siglo XXI de España, 1992.

9. Irigoyen, Renán, Esencia del folklore de Yucatán, Mérida, Gobierno del Estado de Yucatán, 1976 ( $3^{\text {a }}$ edición).

10. Ligorred, Francisco, Consideraciones sobre la literatura oral de los mayas modernos, México, Instituto Nacional de Antropología e Historia, 1990.

11. Отто, Rudolf, Lo santo. Lo racional y lo irracional en la idea de Dios, Madrid, Alianza Editorial-El libro de bolsillo, 2007.

12. Pinkus Rendón, Manuel. De la herencia a la enajenación. Danzas y bailes "tradicionales" de Yucatán. México: Universidad Nacionales Autónoma de México, Coordinación de Humanidades, Unidad Académica de Ciencias Sociales y Humanidades, Instituto de Investigaciones Filológicas, Centro de Estudios Mayas, 2005.

13. Quintal AvilÉs, Ella F. et al. , "U lu'umil maaya wíiniko'ob: la tierra de los mayas”, en Diálogos con el territorio. Simbolizaciones sobre el espacio en las culturas indígenas de México, Vol. I, Alicia Barabas (coord.), México, Instituto Nacional de Antropología e Historia, 2003a, pp. 275359.

14. Quintal Avilés, Ella F. et al., "Solares, rumbos y pueblos: organización social de los mayas peninsulares", en La comunidad sin límites. Estructura social y organización comunitaria en las regiones indígenas de México, Vol. 1, Saúl Millán y Julieta Valle (coord.), México, Instituto de Antropología e Historia, 2003b, pp. 291-382.

15. Quintal AvilÉs, Ella F., “Way yanóone: aquí estamos. La fuerza silenciosa de los mayas excluidos", en Visiones de la diversidad. Relaciones interétnicas e identidades indígenas en el México actual, Vol. II, Miguel A. Bartolomé (coord.), México: Instituto Nacional de Antropología e Historia, 2005, pp. 289-371.

16. Redfield, Robert y Alfonso Villa Rojas, Chan Kom: a maya village, Chicago, The University of Chicago, 1962. 
17. Ruz Sosa, Mario H., "Los mayas peninsulares", en Los mayas peninsulares: un perfil socioeconómico, Mario Humberto Ruz Sosa (coord.), México, Universidad Nacional Autónoma de México, Instituto de Investigaciones Filológicas, Centro de Estudios Mayas, 2002, pp. 10-45.

18. Ruz Sosa, Mario H., Los mayas ( $2^{\text {a }}$ parte), México, Programa de las Naciones Unidas para el Desarrollo, Comisión Nacional para el Desarrollo de los Pueblos Indígenas, 2006.

19. Ruz SosA, Mario H. (coord.), El Campeche maya: atisbos etnográficos, México, Universidad Nacional Autónoma de México, Coordinación de Humanidades, Unidad Académica de Ciencias Sociales y Humanidades, 2007.

20. Terán, Silvia y Christian Rasmussen, La milpa de los mayas. La agricultura de los mayas prehispánicos y actuales en el noreste de Yucatán, Universidad Nacional Autónoma de México, Centro Peninsular en $\mathrm{Hu}-$ manidades y Ciencias Sociales, 2009.

21. Terán, Silvia y Christian Rasmussen, Xocen, el pueblo en el centro del mundo, Mérida, Universidad Autónoma de Yucatán, 2005.

22. Villa Rojas, Alfonso, Los elegidos de dios. Etnografía de los mayas de Quintana Roo, México, Consejo Nacional para la Cultura y las Artes, Instituto Nacional Indigenista, 1978. 


\title{
Abstract, keywords, about the author
}

\begin{abstract}
This study sheds light on a sacred entity that is firmly rooted, and continues to be highly relevant, in the cosmology and culture of the present day Mayan Indians from the Yucatán peninsula in Mexico. Using ethnographic data collected in native communities from the state of Campeche, I will illustrate how these revered beings, the aluxo'ob, are the receptors of abundant offerings via the Mayan campesino's annual ritual activity, as well as their role as protagonists in a diversity of mythological narratives that explain the genesis of the world and the successive creations and destructions of humanity. Finally, I will explore the links that connect the ritual Mayan specialists (jmeen) with the aluxo'ob, whom they seek for the esoteric knowledge necessary for mediating the relationship between their communities and the sacred realm.
\end{abstract}

Keywords: Peninsular Mayans, aluxo'ob, cosmology, ritual, jmeen

David De Ángel García is a Full Researcher at the Centro Peninsular en Humanidades y en Ciencias Sociales of the Universidad Nacional Autónoma de México, located in Merida, Yucatan.

E-MAIL: corle_spck@yahoo.es 